\title{
The Effectiveness of Using Ning Social Network on High School Female Students' Achievement in English
}

\author{
Haya Suliman Al Jasser
}

\begin{abstract}
This study aimed at measuring the effectiveness of Ning social network on high school female students' achievement in English. The researcher has used a quasi-experimental methodology to examine the effect of the independent variable: the use of Ning social network on the dependent variable: the achievement of senior high school students. The study group included all senior high school students enrolled in public high schools in Riyadh province. The total sample consisted of $(\mathrm{N}=42)$ students, divided into two groups : an experimental group, consisting of 21 students taught using Ning social network for two weeks, and a control group of 21 students taught by the traditional method. All students were administered both a pre-test and post-test in English Language achievement. Results showed a statistically significant difference between the average achievement of the experimental and control groups. For the experimental group.

In light of the results obtained, the researcher presented a number of suggestions and directions for future research.
\end{abstract}

Index Terms-Ning social network, e-learning.

\section{INTRODUCTION}

The last decades of the twentieth century are characterized by the astounding pace because of the great development in the field of communication \& its means, followed by successive developments in the sectors of media and information; which had an impact on the components, means and processes of the culture. Many reputable scientists agree unanimously on the information revolution which translated into what was called (the Internet) it is the most important technological achievement happened until now; the man could eliminate distance, shorten time \& makes the world more like a small electronic screen at the time of mixing between information and media technology, culture and technology. Communication has become electronically, allowing quick access to science and knowledge centers, libraries and seeing the new day by day, and moment by moment [1], [2].

Contemporary education - as a general field ,has been affected by the cognitive and technological revolutions in the last decades of the previous century and the first years of this century; which called for the possibility to make a significant development in educational practices within our educational institutions in all stages, types and levels [3], [4].

As a result of these changes, many modes and methods of teaching have appeared, especially in the area of individual or self- education, in which the learner is going according to his capacity, ability and speed of learning, according to his

Manuscript received March 23, 2017; revised May 19, 2017.

Haya Suliman Al Jasser is with King Saud University, Saudi Arabia (e-mail: hajaser@gmail.com). previous experiences and skills used as solutions in the face of such changes, thus the concept of programmed learning , the concept of learning by using computer, and the concept of distance education have emerged in which a student learns at anywhere, without the need for a permanent teacher.

And on the basis of the huge revolution in information and communications technology, its modern technological means have transformed the world into a global village. This has a huge impact on the field of education, a new type of education based on information and communication technologies known as electronic learning has appeared, based on modern technology of computer and the World Wide Web, multimedia) CDs, educational software, e -mail, platforms of dialogue and debate, and virtual classrooms to deliver information to the learner [1].

ELearning also depends on learner's participation in educational activities; creating an atmosphere of interest in the learning process, and a desire to go on with it, unlike authoritarian methods of education that create an atmosphere of aversion.The learner acquires the skill of how to learn (Learning to Learn) which means the continuation of the process of acquired learning for life on one hand, on the other hand, there is motivation, appropriate tendencies to the learning process, and also serves to help the individual learner to develop himself [5]-[6].

The advantages of e- learning: it expands the boundaries of learning, facilitates the process of learning in the classroom, home, and workplace. E-learning is considered a flexible form of education; because there are alternatives to the learners in terms of place and time of their learning [7].

The participants in e-learning have nothing to fear; their views have been sent by a technique which does not allow anybody to watch them; where guidance is done for the correct answer through discussion among the students. In addition, the work by written means, and in the absence of direct observation provides an opportunity for participants to focus on the meanings and content of messages, and because of that ideas evolve, and become more mature. The ability to collaborate and create knowledge are two indicators of meeting a virtual educational community and success. As the diversity of traditional e-learning tools and second-generation e-learning tools including blogs, RSS feeds, (Wiki) and Social Networks, learners are provided with multivendor rich environments in research and self-development [1].

A recent trend has emerged toward using social media networks in the learning process, because of its characteristics that facilitate active interaction among members participating in the network, such as: (immediate correspondence, video, chat, file sharing, discussion groups, e-mail, blogs). They are called social as they derive from the 
concept of "building communities", in this way, the user can identify individuals with common concerns in the Internet, identify additional sites in the areas of interest, share photos, memories and files, with the family, friends and colleagues; [8].

On line social networks allow to participate in the edit and update of the content of the pages in several ways, including: modification, inserting a comment or (Upload) media file from the user's computer to (Server) everyone can read, type, and share without the need to learn a programming language, only by typing the text directly, as in dealing with a word processing program in a personal computer, a student can control the time, the way he learns through what social networking technologies provide of potential.

A number of psychologists \& linguists state that the human brain storage process of information, vocabulary is determined by the nature of the psychological state of the recipient, and as we find this idea is supported by the Greek philosophy. As Aristotle said in his talk about the theory of knowledge on the need to adhere to dimension of entertainment during the process of teaching lessons; therefore, these websites will be the most things that can generate a revolution in the field of education if it is employed in accordance with requirements of the discourse of knowledge and science. The theories of psychology emphasize that social communication is the biggest reinforce of higher mental processes [9].

The emergence of websites such as Face Book, My Space and Ning led to attract a large number of Internet surfers, they became the most popular web browsing sites. Social networking services have emerged as a main component of the Web 2.0 movement, which worked on the use of network-based computer to connect people to each other, to exchange information and increase the ability to learn, especially English language learning, it provides learners with greater space and freedom to practice language with their teachers and peers.

Because of the nature of the researcher's job as (a teacher of English at the secondary level), seeking the need to take advantage of Social networks in teaching English, the purpose of this study emerged to explore the effectiveness of using Ning social network on secondary school female students' achievement in English.

\section{Study Problem}

Despite the growing interest in English and its proficiency as it is considered one of the most important conditions to enter the labor market and one of the main requirements to join it, the weakness in learning English is still clear; the attention is always focused on translating texts and understanding grammatical rules without any attention to the application and practice of language in daily life.

As noted the low level of secondary school female students' achievement in English and the inability of the current teaching methods for providing the needed skills to learn English, which leads to use modern technologies, where the employment of technology in the service of education helps to take into account individual differences, provide feedback to the learner, increase achievement , acquire learning skills and learning skills of using computers is used in the teaching process, acquire positive trends and tendencies, reduce the time of learning, develop problem solving skills, implement many difficult experiences, install and explain concepts, keep historical facts and reduce the burden on teachers .

In the light of the above and researcher's experience in the educational field (a teacher of English at the secondary level), research problem is summarized in finding ways of modern technology to develop the skills of using English, ensuring further motivation of learners to use English without any shame of making mistakes and providing more opportunities for female students to practice English outside the classroom by using Ning social network. The study problem is identified to answer the following question:

What is the effectiveness of using Ning Social Network on high school female students' achievement in English?

\section{A. Study Questions}

1) Is there a statistically significant difference between the mean scores of the two groups of students? The experimental and the control groups in the pre application of achievement test?

2) Is there a statistically significant difference between the mean scores of the pre test and post test of achievement test among the control group?

3) Is there a statistically significant difference between the mean scores of the pre- application and post application of achievement test among the experimental group?

4) Is there a statistically significant difference between the mean scores of the experimental group students and the average scores of the control group students in the post application of achievement test in English course?

\section{B. Reasons for Choosing Ning Network}

The researcher has chosen Ning social network for technical reasons represented in the presence of additional features that distinguish this social network from other social networking sites. The main idea of Ning social network is to allow users to establish their social networks, join and participate in other networks.

Ning also allows networks designers to identify the appearance and function of the site and whether it is a public or personal site. Most sites contain features; such as: images, videos, lists of the network's members, events, and groups within the network and means of communications such as forums and sites that do not require a technical skill to design a social network in Ning and there are no limits to a number of networks in which a user can join.

Ning also provides cost free networks assisted by advertising, or users can pay a proportion of services to remove ads that allows users to select a site's title, separate from Ning's control. Ning's network also provides a way for teachers to make use of social networks in a neutral way, and thus providing a familiar and comfortable experience and function for students. Establishing social networks of academic subjects, or special projects of academic subjects enables the learner to extend a strong sense of unity among students, and encourage personal interactions that could lead to the creation of new knowledge and collective intelligence, similarly the discipline of specific social networks linking 
researchers from all over the world to work on particular topics of the study.

This technique allows the learner to master the skill, depending on Self Paced learning through training on writing selection of relevant topics to write about, or making language conversation with others, to master the skill depending on Self Paced learning; this technique provides self-learning skills, which are survival skills, survival skills, this is embodied in the individualization of education [10].

\section{Study Objectives}

This study aims at:

1) Exploring the effect of using NING Social Network on female students' achievement in English.

2) Increasing female students' motivation to practice English through NING Social Network freely, aside from a female teacher's direct supervision in the classroom.

3) Increasing female students' vocabulary by expanding learning scope beyond the classroom and class time.

\section{Study Significance}

This study has its overall importance of the area it covers (using Ning Social Network) the stage in which it is taking place (secondary level) the institution (school), its significance can be identified as follows:

1) The need to keep abreast of scientific and technical progress, which we live in the present time, where techniques of Social networking are now within reach of millions of users everywhere, and at any time, such as (My Space , Face Book, Ning, etc.) as the evidence indicates the existence of 250000 new registrations in these techniques every day.

2) Results of this study can provide important information on the positive role of Ning social network in English teaching and increase female students' motivation to practice it on a large scale; and thus it may encourage female teachers of English to activate, and combine it into the Educational process.

\section{E. Study Hypotheses}

To answer the study questions, the following hypotheses will be tested:

1) There is no statistically significant difference between the mean scores of the two groups of students: the experimental and control groups in the pre application of achievement test.

2) There is a statistically significant difference between the two mean scores of the pre application, and the post application of achievement test among the control group.

3) There is a statistically significant difference between the two mean scores of the pre application, and the post application achievement test among the experimental group.

4) There is a statistically significant difference between the mean scores of the experimental group female students and the mean scores of the control group female students in the post application of achievement test in English course.

\section{F. Study Limitations}

1) Objective limitations: English course for the third secondary grade.

2) Spatial limitations: some schools in Riyadh city.

3) Time limitations: first semester of the academic year 2012.

\section{G. Study Terms}

\section{1) Social networks}

A system of social networks that allows the participant to create his own account, and then connect it through an electronic social system with other members who have the interests and hobbies, or combine with university, or high school colleagues. They are called social as they derive from the concept of "building communities" in this way, the user can identify individuals with common interests in the Internet, explore more sites in the areas of interest, share photos, memories and files with family, friends, and colleagues [8].

2) Ning social network

A service that allows users to establish their social networks, join and participate in other networks. Ning allows networks owners to determine site appearance and function and whether a web site is private or public. It includes features such as images, videos, lists of members' names of the network, events, and groups within the network, and means of communication such as forums, websites and blogs [11].

3) Procedural definition of Ning social network

It is a social network with characteristics that allow learners to administer their relationships, hobbies through a wide range of services as they can exchange information, experiences and join several other sites at the same time, it also does not need a technical skill to deal with Ning social network where there are no limits to a number of networks in which a learner can join.

\section{4) Procedural definition of (traditional method)}

A method used by the teacher to explain the lessons of the unit content: Earth \& its Neighbors of English course for the third grade high school.

\section{5) Secondary stage}

It is the final school stage of general education in the kingdom of Saudi Arabia. It starts after achieving intermediate qualification certificate or its equivalent,. The study's duration of this stage is three years ending with secondary qualification certificate [12], [13].

\section{THEORETICAL FRAMEWORK}

\section{A. Introduction}

The Internet is a means of communication between computers, and units of services to one another around the world; to make data flow on the Internet and be received by a number of ways; the most famous of these ways: Using the graphical user interface, known as the international web network. The number of Web sites is increasing very fast; because of the rapid tremendous development of information technology [14].

With the rapid growth of the Internet and digital 
technologies, the Internet has become a strong, international, interactive, economic and democratic, environment for education, and distance learning; [7], therefore, it gives an opportunity to develop education and training based on the learners, at any time they require [7].

During the 1990s, the Internet industry sought to provide its users with the content they were looking for via a web-based transmission network, and a large number of millions of Internet browsers around the world can receive this broadcast, and then Internet developers could use Internet browsers to send and receive the data at the same time, rather than its original role as a blind receiver of data, beginning at e- mail applications, chat, dialogue forums, and finally the most modern revolutionary electronic applications like Wikipedia encyclopedia.

\section{1) Web concept}

The web is a system of hypertext documents related to each other working on the Internet. The user can browse these documents using a web browser, and can move between those pages via hypertext links. These documents contain plain text, images, and multimedia. The web in the past contained static pages (HTML) and rarely are updated.

The web 1.5, which is a "dynamic web, which has web pages immediately from the database contents by using content management systems.

The Web 2.0 is more than dynamic web pages, it is a social network with greater reliability to the users (see Fig. 1).

The jump in the way to change the technique of dealing with Internet browsers, is the real beginning of what is known as the Web 2.0 applications [8].

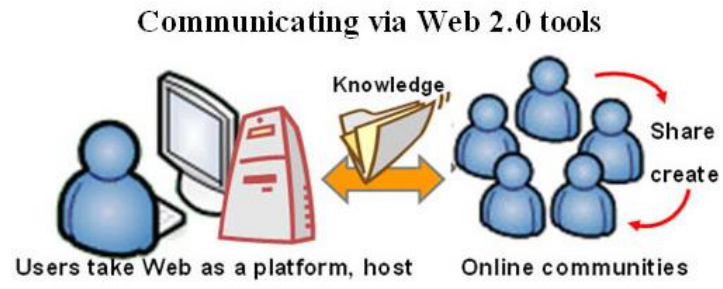

Fig. 1. Communication via web 2.0 applications.

2) Definition of the second generation of the web 2.0

The Web 2.0 is a new technique to provide second-generation services from the Internet, relying on the support of communication among Internet users, and maximize the user's role in enriching the digital content on the Internet, cooperation among different Internet users in building electronic communities, this mechanism is reflected in a number of applications that meet the attributes and characteristics of Web 2.0 most notably (Blogs), (Wiki) Content Tagging), (Online Social Networks) and (RSS).

3) Emergence of the second generation of (the web 2.0)

It was the first appearance of the term (Web 2.0) in (Web 2.0 Conference) organized by (O'Reilly company) It emerged as a result of brainstorming in a meeting held on the margin of the conference between O'Reilly, and (International Media Live) companies where they defined (Web 2.0) as a set of sites, services and applications in which there are a number of features [15].

4) Main important services provided by (the web 2.0)
The second generation of (the Web 2.0) provides services such as: Blogs, Wikis, (RSS) Feeds, (Multimedia Files Sharing), Podcasting and audio blogs , (Social bookmarking), and (Social Networks) such as (Face Book),(My Space), (Ning), etc. [15].

\section{5) Social networks}

Social networking sites have become a universal phenomenon deserve attention, providing electronic communities, such as (My space) and (Face Book)which provide several services, including: personal accounts of millions of individuals free of charge, persons who have been invited, or joined to these communities can publish an electronic content of multimedia about their hobbies and personal interests. And they can communicate with their friends or explore new friends with common interests.

Social networks allow to build social relations among people from all over the world, different cultures and nations , the user can access information, or trade, and even the overall participation with others by sharing information and content through the Internet [16].

\section{6) Emergence of social networks}

The first appearance of social networks was in the late twentieth century, when the site of (Classmates.com) emerged in $1995 \mathrm{AD}$, then followed by (Six Degrees.com). These sites depended on establishing personal pages to users, and sending messages to a group of friends, but these sites were closed; because they did not bring profits to their owners [8].

\section{7) Definition of social networks}

Wikipedia defines social networks as a term given to a group of websites emerged with the second generation of the Web, or the so-called Web 2.0 which provides communication among individuals in a virtual community environment shared by groups of interest, or networks of affiliation (country, university, school or college.. etc.) all this is through direct communication services such as messaging, access to personal files of others and view their profiles and information which they allow to display.

Reference [17] defined social networks as "available communities via the Internet, consist of persons who share the same interests and activities, or they care about exploring the interests, and activities of others. These networks usually provide various and several ways for users to interact through conversation, correspondence, or by e -mail" [17].

In the present study, the researcher has adopted the definition of Al Amoudi [15], who defined social networks as:" programs that support group activities to consolidate human relations and build knowledge on the web. Cyberspace provides a rich choice for real life. These programs enable learners to use digital technologies to benefit each other by participating in building knowledge."

8) Services provided by social networks

Social networks share the basic characteristics, while other networks differentiate from each other with other features according to the nature of the network and its users, the most prominent of these characteristics are:

- Establishing (Personal Profiles) and (Personal Pages)

Through personal profiles you can identify the person's 
name, and basic information such as gender, birth date, country, interests, and personal photo in addition to other information. A personal profile is considered an access point to the person's world, and through the personal home of a personal profile, you can look into the person's recent activity, to recognize your friends by the content they're uploading and so on.

- Building communities of (Connections / Friends)

They are individuals whom a person recognizes for a specific purpose. Social networks give a name: "A friend," to this person added to your friends list, while some social networking sites for professionals entitle: "connection or relationship " to that person added to your list.

- Messaging:

This feature allows the possibility of sending a direct message to the person, whether in friends' list or not.

- Establishing photo albums:

Social networks allow users to create an infinite number of albums and upload hundreds of photos, and allow to share these photos with friends to view and comment on them.

- Establishing groups of interest.

Many social networks sites allow their users to create \& establish a group interest with a given title and specific targets. A social network site provides its members and a group's owner with space more like a mini forum for dialogue, and a mini photo album, it also provides the feature of coordinating meetings through what's known as (Events), inviting members of that group and identifying the number of attendees.

\section{- Home Pages}

This idea was invented and used commercially in an effective way by (Face Book). where it is currently working on building a directed advertising campaign, allowing for owners of commercial products or events to manage their pages to show to a group of users. Face book deducts a sum of money for each click accessed by any user who is clicking on the advertising, the idea of establishing pages is to present information of product, event or personality, then users surf these pages by specific divisions of specific pages, and if they find any attention to that page, they add it to their profile.

\section{9) Classification of social network}

Digizen's organization [18] interested in promoting the safe use of the Internet, classifies social networks into:

- Social networks provide a personal profile of the user

These networks often provide a personal page for the user, as an example of this type of social networks (Face Book) and (My Space) Users develop their personal pages in these networks in different ways, and contribute to the development of others' web pages either by a comment or adding links to external contents [18].

- Social networks based on the content

These networks support the content basically, they also provide a user's personal page, but less important than the content, the famous photo sharing site (Flicker) is considered a model for this type of social networks; where all the comments are about pictures, and other examples of this type of networks:(Shelfari) where the digital bookshelves are an interface among user [14].

- Free social network
These networks enable members to build or join electronic communities, which means that users can build their own networks on any topic they want, a group of people can become members of a given social network, allowing them to add and share information on the topic that has been selected previously with other members, examples of this type of network: the network: (WetPaint) network.

- Multi-user virtual environments

It is a three-dimensional virtual environment on the Internet, allows each user to find a virtual character for himself, known as (Avatar) where members interact with each other similar to real life, examples of such environments: (Second Life) and (Runescape games environment)

- Mini blogs

They are social networks websites provide a micro blogging, and allow their users to send updates directly through the web site, or by sending an (SMS) instant messenger programs, or applications submitted by developers; the most famous of these networks are (Face Book) and (Twitter)

- Social networks search

Such networks provide access to lists of users of many social networks which enable the user to search for a member's name, location, hobbies, or any other information that has been posted in general [18].

- Mobile social networks:

These networks provide access and benefit from its services, via computers and smart phones such as (Face Book), (Bebo) and (Ning) [18].

\section{0) Ning social network}

Ning is an online service that allows users to establish their social networks, join and participate in other networks. It also allows the Network creators to determine the appearance and function of the site, and whether it is private or public. Most websites contain features; such as: images, videos, lists of network members, events, members within the network and means of communication, such as: forums, sites, where it does not require a technical skill to establish a social network, there are no limits to the number of networks that a user can join [19].

Ning network also provides cost free networks assisted by advertising, or users can pay a proportion of services to remove ads that allows users to select a site's title, separate from Ning's control. You can access Ning social network through the following link http: www.ning.com.

\section{1) Users of Ning social network}

Although Ning doesn't provide statistics of the number of registered users, the network establishes a number of networks on its platform periodically, Ning announced that it contained 220.000 networks. By browsing available ning networks, they focus on a wide range of topics, use various activities, such as: news, current events, entertainment, intellectual development, and support team.

Some international users have established quite a number of networks, as a regional or local interest as well as some organizations use Ning to develop a social network that completes its main site, while others resort to Ning as a forum for an organization or institution's site.

Some networks also focus on specific commercial 
products, and in some cases, representatives of products are even more active in the network, which becomes a tool of a social advertising. We also find a lot of formal and informal groups of graduates of secondary schools as well as colleges and universities use Ning to develop their social relationships, where they can communicate, share experiences and information.

\section{2) How to establish Ning network}

Ning network could be easily used where registered users can establish networks in a short time without the need for a technical skill. As soon as a name and a site's title are selected, a network clustering is a simple process to work through four screens, the user indicates whether the network is personal (he can join and view invited persons only), or public (open to all); ,writes the tag line, the network description, specification of words, and choices of the selection features; such as: (pictures, videos, electronic sites, events, groups, or tools), or visual interface options; (colors, fonts, and spaces), and uses drag and drop tools to put these features on the page.

Ning network user can codify these options, and identify the information users need to join the network; if a membership is restricted, an account creator may invite individuals to join by sending a link (URL) to their e-mail for access, allowing creators to link to other networks ; such as: taking photos from (Flicker) or adding (Ning) features to (Face Book) pages or log to a source code for more network codifying, including JavaScript, which allows external tools to follow statistics of using the network.

Ning social network also characterized by its flexible applications and susceptibility to deal with other networks, where services can be shared between the network and similar networks such as (Face Book) and (My Space) which support network use processes, and enrich the number of users [11].

\section{3) Previous studies}

Many of the previous studies discussed the use of social networks for educational and training purposes, the researcher classified them according to the following areas:

- First: studies on the trend towards the use of social networks.

- Second: studies on the effectiveness of social networks in promoting teaching and learning processes.

- Third: studies on the effectiveness of social networks in training.

First: studies on the trend toward the use of social networks:

A number of previous studies examined the attitudes of students and faculty members with the use of social communication networks in education and effectively used in formal learning environments. Among these studies ,the study of Edwards \& Deed [20], which involved measuring students' attitudes towards the use of social networks in an academic context of higher education at La Trobe University in Australia, and the effect on knowledge building growth. The researchers collected the data through a questionnaire on the Internet of a sample consisted of 200 students. Data was analyzed by using Bloom's cognitive levels [20].

The study found the need to provide students prior knowledge \& skill by using social media technology in order to build knowledge in an academic context. Effective learning takes place only by learners during learning and providing technical expertise and knowledge [20].

A study by Mazman \& Usluel [21] from (Hacettepe) University in Turkey, develops a model that identifies the factors that affect the adoption and extension of social networks for the use in an educational context which are: easy to use, and the use of social networks, social factors, innovation, technical support, subjective criterion, society culture, and the user's general image. These elements are interdependent, and affect each other [21].

The study also discussed a number of important issues emanating from them, and conducting further research, such as: motivation issues, the extent of user satisfaction, positive interaction between (the learner and the teacher, the learner, and peers.), and social presence [21].

This study is consistent in terms of the importance of using social networks in education with the study of Wolf [22] which explored the views of liberal arts college students about the use of social networks via the Internet, their attitudes and behavior towards that contained models of learning and information presented earlier. The study results revealed a successful and accepted model of using social networks [22].

The results of this study showed that there was a need to classrooms' experiences that enable students to cope with the increase and growth in life interaction, especially in areas where positive interactions are evident in the classroom, as well as activating the information on the Internet to be considered. In this age, social networks used by students happily, reflecting the importance of that change that must occur to the culture of public education [22].

The study of Erzurum \& Tiryakioglu [23] attempted to explore the attitudes of faculty members in the Department of Communication Sciences at the University of Anatolia in Turkey towards the use of Face Book as a way of communication. The study sample consisted of 67 professors with various academic levels. The study found that the use of Face Book is an effective way to communicate and share experiences, where all faculty members agreed on that [23].

The study also showed that younger faculty members use Face Book and similar techniques in their courses more than older faculty members [23].

The study of Brady \& others [24] aimed at studying the benefits of online learning through Ning in education. The study population consisted of faculty of education students at the University of California. The sample was selected from students enrolled in a distance education course totaling 50 students. At the end of the semester, participants were asked to complete online survey about their attitudes and perception of (Ning) as an educational tool for E-Learning based on their experience [24].

The study found that the use of Ning in education is much more convenient than the classroom where students meet face-to-face, share and discuss ideas, because the use of Ning network enhances the possibility to communicate with others who have different experiences in any time and any place [24].

Second: studied on the effectiveness of social networks in 
promoting teaching and learning processes.

A number of studies addressing the effectiveness of using social networks to enhance teaching and learning processes including the study of Kamat \& Metha,2009 [25] which sought to identify the impact of using (Face Book) as a social network and others on education [25].

The study was conducted on 20 students in the "Master of Instructional Technology and Computer Applications" or so-called (METCA) program , being provided to women's University (SNDT) in India, the sample consisted of 19 students. The quasi experimental method was applied. The pre and post achievement test was used as a study tool to explore students' views before the study through a website about the extent of using social networks in their daily life. One of the main objectives, researchers can study the effectiveness of (Face Book) as an effective means of teaching and learning [25].

The results showed that a rate of $79 \%$ of the sample participating in this study classified Face Book from good to excellent as a tool for social communication, reflecting the quality of this means in social communication via the Internet, according to the survey, the study found that the learners have found that the use of Face Book is a good means, while a rate of $84 \%$ of the sample classified (Face Book) from good to excellent in education, and in this part, the sampled was required to use Face Book, and determine whether they wished to continue using Face Book during their learning process [25].

This study agreed to a large extent with the study of (Juang, 2010) which sought to identify the importance of using social networks in teaching and education. This study adopted a popular social networking site Face Book to apply (WIRE) model. The experimental method was used. The sample consisted of second year students in college majored in information management [26].

The sample was divided into an experimental group, consisted of a class containing 50 students and a control group consisted of another class containing 38 students. In order to ensure homogeneity of the two groups, a pre- test was conducted, its results have showed that there are no statistically significant differences [26].

The social network (Face book) was used with the experimental group, while no technique was used with the control group. The results of this study have showed there are statistically significant differences between the two groups for the experimental group in the post test, this shows that the use of social networking sites can improve achievement in education. Face Book can also increase achievement in education and it increases motivation and interaction when adopting (WIRE) model that consists of initialization, review and training on lessons in the classroom [26].

The study of L. Lockyer \& J. Patterson [27] aimed at recognizing the importance of integrating social networking technologies in the formal learning environment, the sample consisted of graduates (higher studies students) (lecturers and students). Flicker social site was used where students have been provided with information about the site and then they were asked to establish a free account [27].

The student takes a digital image of a subject and puts it on the site with a brief description of the image content, then his students comment on images. The lecturer created a discussion forum where students comment or ask questions about their activities. The results of the study showed that students learned a technique by a technique and expressed the wish to use Flicker in several ways in private areas of their work. Through the analysis of students' comments and description across Flicker, there is a reasonable level of cognitive participation in the course. In general, it can be said that this experience is the use of social networking sites in a formal learning environment resulted in positive results and good experiences, such as the employment of pedagogy in the web 2,0 technologies in order to maximize the use of social networking sites in education. This study indicated some interesting issues in the field of teaching and education and in the technical area associated with the Web 2,0 social technologies to support formal learning environments such as focusing on the learner's role, identifying effective learning strategies in such environments [27].

The study of Al Khathlan [28] on the effectiveness of (Podcasting) to develop speaking skills in English course as a second language. The research is identified by a purposive sample consisted of 40 students of high school female students [28].

The researcher used the descriptive method and the quasi experiment method of two groups: the experimental group which received treatment to broadcast Podcasting episodes containing audio files for a month. The control group taught by the traditional method, after achieving equality between them and regulating the research variables.

After conducting statistical treatment of the post test, the results showed the effectiveness of (Podcasting) technique to develop speaking skill in English. The researcher attributes the effectiveness of a technique, such as Podcasting on speaking skills to modern technology, and its relation to portable devices such as multimedia players, mobile phones, and all devices that contain RSS feeds like (Xbox and PlayStation 2). Students deal with technology as a kind of education with entertainment [28].

Most students and female students in different learning stages are fond of the acquisition of these devices which increase motivation to participate in learning. Also, the fact that (Podcasting) technology promotes constructivism theory which makes the learner an active participant in learning and helps survival of learning impact [28].

The study of Oradini \& Saunders, [29] reviewed the reality of the use of social networks by faculty members and students in (Westminster) University which found that students and faculty members can take advantage of the closed social network (Connect) founded by the university to connect and largely facilitate communication between students and faculty members [29].

The study results emphasized the importance of the effective participation of faculty members through (Connect) network to encourage and stimulate students to participate regularly and with more focus. Perhaps the most important result of the study is the importance of linking social networks to management learning systems, such as (Blackboard) to create an integrated social learning environment [25].

Third: studies of the effectiveness of social networks in 
training.

The study of Aluri, [30], which sought to identify the effectiveness of using social networks on functional improvement among a sample of students at college of hotel management and their attitudes towards it at Oklahoma State University. The researcher used the survey method to collect and analyze the data. This study found students' satisfaction for using social networks to share information due to ease of use and multiple potential. Social networks also provide for students marketing opportunity for their qualifications and skills to get better jobs in companies and institutions [30].

\section{StUdy PROCEDURES}

\section{A. Study Methodology}

A quasi experimental method was used to be as follows:

TABLE I: THE QUASI EXPERIMENTAL DESIGN OF THE STUDY

\begin{tabular}{clll}
\hline Group & \multicolumn{1}{c}{ Pre-Test } & $\begin{array}{c}\text { Teaching } \\
\text { method used }\end{array}$ & \multicolumn{1}{c}{ Post- Test } \\
\hline \multirow{2}{*}{$\begin{array}{c}\text { Experimental } \\
\text { Group }\end{array}$} & Achievement & Using Ning & Achievement Test \\
& Test Application & $\begin{array}{l}\text { Social } \\
\text { Network }\end{array}$ & Re -application \\
Control Group & Achievement & $\begin{array}{l}\text { Using } \\
\text { Traditional } \\
\text { Test Application }\end{array}$ & $\begin{array}{l}\text { Achievement Test } \\
\text { Re -application }\end{array}$ \\
& & & \\
\hline
\end{tabular}

\section{1) Study population}

The research population consisted of all the third secondary grade female students attending education schools in the academic year of 2012 , The first semester.

a) Study sample and reasons of selection

1) A Purposive Sample was selected from the third secondary grade female students totaling (42) female students. Riyadh region was chosen as the researcher work in it as an English teacher in the secondary level. The public high school ,Eighty- one, was selected in a Purposive way in Al Aqeeg district, Riyadh city due to the similar economic and social conditions of female students, the convergence of their educational level, the availability of potential, equipments ,acceptance of female teachers and female students and their readiness to conduct the experiment.

2) Two classrooms were selected from a total of four classes of the third secondary grade, science department. The two classrooms were divided in a randomly simple way by using the lot where third secondary grade class one, science represents the experimental group female students, with a number of (21) female students, third secondary grade class two, science represents the control group ,with a number of (21) female students and thus the number of the sample members represented in the experimental and the control groups (42) female students. The experimental control has been achieved, represented in the female teacher's teaching for both groups, and becomes equal a number of female students in both classrooms, and the similarity of economic and social conditions in both classrooms

b) Controls of the experimental design of the study

A number of variables was controlled, that can influence the research results as follows:

- The teacher was directed to teach the two groups: the experimental and control groups with the same effort and interaction, so that there will not be a difference between the two groups except in the independent variable (Ning Social Network) of the experimental group and (traditional method) of the control group.

- The Academic content itself was taught, represented in the module five of English curriculum of the third secondary grade female students of the first semester.

- The pre and post achievement test was applied.

\section{B. Study Tool}

a) Achievement test

The researcher used an objective achievement test prepared by her, consists of (15) items according to the objectives linked to the topic of module five (Earth \& Its Neighbors) in order to collect the data necessary to test the hypotheses of the study to measure (the effect of using Ning social network on achievement)

b) Apparent validity

The extent of apparent tool validity was measured by achievement test on a group of arbitrators: (university professors, specialists in education, English educational supervisors, English female teachers) to explore their views about apparent validity in terms of its significance, clarity of terms, and suitability of its terms for measuring what it was developed for, in the light of arbitrators' observations and instructions, the test was produced in its final form.

c) Reliability

To verify the reliability of achievement test, Cronbach's Alpha reliability coefficient was used, the value of reliability coefficient was (0.843), it is a good value, it indicates that the test is characterized by appropriate reliability coefficient of achievement test.

\section{Study Measures}

3) A review of studies and research related to learning through social networks.

A site preparation to be used in the study application in which the researcher will select a clear name for the site by purchasing a domain name for easy access from the search engine. (www.haya-efl.ning.com) by using a user name and password.

The researcher's site was posted on Ning Social Network, which was used in teaching the experimental group and it was checked for validity with a questionnaire of arbitration which was presented to a group of arbitrators (university professors, specialists in education from educational supervisors ,instructional designers) to ensure the effectiveness and relevance of the site to teach the experimental group.

A user's application interface of social network , is selected and identifying appropriate features for the study objectives; from a list of various features offered by Ning network to the user.

Uploading files and instruction materials of pictures, video clips on the network.

Adding female students' e-mail addresses in the 
experimental group on the social networking website and they will be sent an e- mail with the site (URL) where they copy the web link from the computer, whether a desktop computer, laptop, iPad, or any of the modern smart phones equipped with Internet service.

The experimental group female students were introduced to social network designed to conduct the study, and ensure they can understand and use icons by preparing a presentation prepared for that, and presented to them. A simple guide (prepared by the researcher) also was distributed to female students on how to use the network. As Ning social network is highly similar to Face Book, the researcher expects that the female students will not encounter difficulties in its use.

Preparation of an objective achievement test according to procedural objectives of the content of unit five: (Earth \& Its Neighbors), then, achievement test is applied in a priori way to the two groups: the experimental and control groups.

The experimental group is taught unit five (Earth \& Its Neighbors) through Ning social network site and the control group is taught the same units by the traditional method..

Re-application of achievement test (post-test) is applied on the two groups: the experimental and the control groups.

The statistical analysis and interpretation of the results.

Writing down recommendations, and proposals.

\section{Application Tool}

An educational strategy is designed by using Ning social network; to develop achievement in English by using one of the educational design models.

(ADDIE) model was chosen.

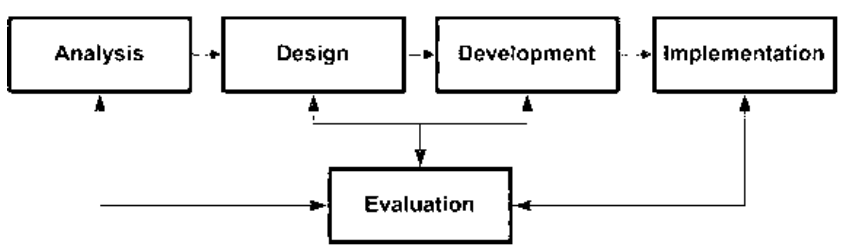

Fig. 2. (ADDIE) model.

(Model Addie) was chosen for several reasons, including:

1) Its steps are clear, specific, and help teachers deal with it systematically and easily.

2) It fits a lot in the learning and teaching process which requires the web based media.

3) Enhancing the constructivism theory that makes the learner effective to participates in building his knowledge [10]-[31].

(ADDIE Model) consists of five main stages:

The model derives his name from them, as follows:

1 - Analysis

2- Design

3- Development

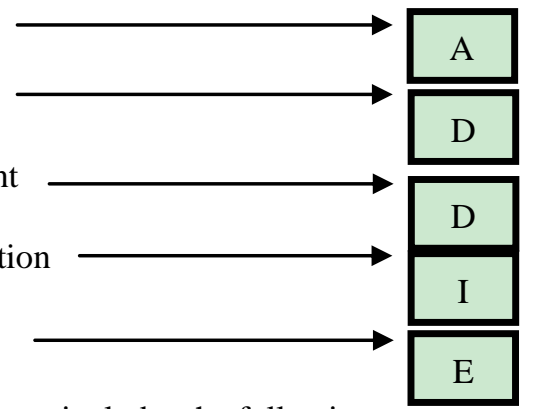

1) Analysis phase includes the following:

- Identifying a problem represented in poor achievement in English.

- Learners' characteristics. Most of them possess basic skills to deal with the computer, Internet, they have a desire for learning through technology.

- The proposed technique represented in using Ning social network in teaching English.

- A content analysis of unit five, entitled Earth and its Neighbors of English course for the third secondary grade of the first semester.

- Identifying educational objectives.

2) Design phase includes:

- Teaching materials are collected from the Internet \& various sources including pictures, videos, and educational websites linked to the unit content.

3) Development phase includes:

- Selecting the appearance of social network and choosing appropriate features for the study objective, from a list of various features offered by Ning network to the user.

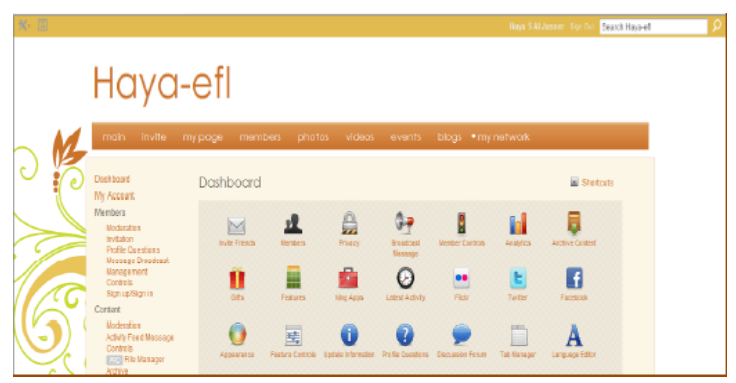

Fig. 3. Ning social network home page.

- Uploading files and teaching materials of pictures and video clips on the network (See Fig. 5)

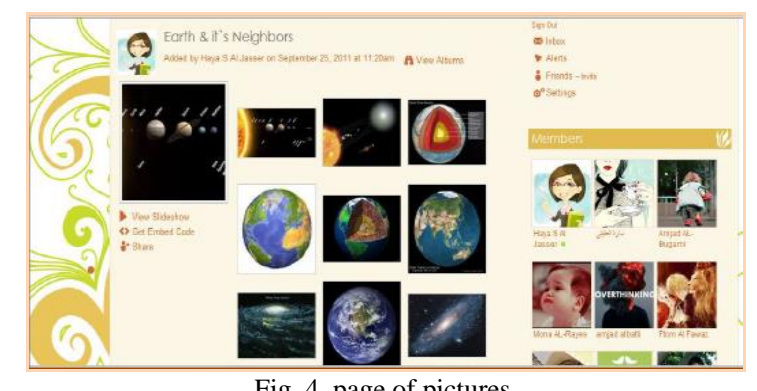

Fig. 4. page of pictures.

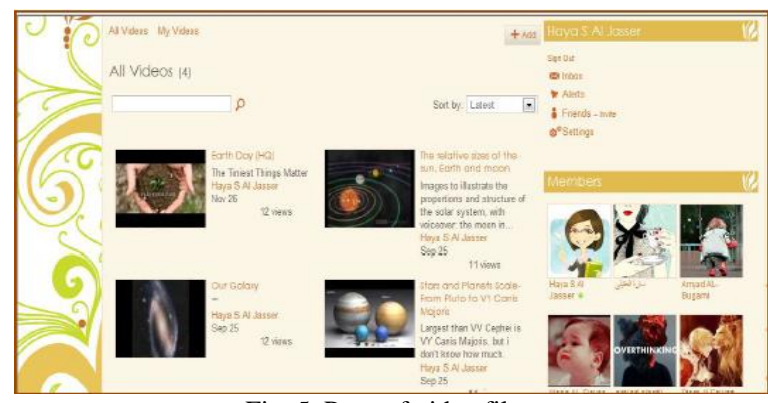

Fig. 5. Page of video files.

4) Implementation phase includes:

- After the preparation of a social network site and making sure of its readiness prior to applying the experiment, female students had a meeting in the learning resource room in school to explain how to make the network, how to join and participate in it. 
5) Evaluation phase includes:

- (Formative) (Summative) evaluation from the views of arbitrators, specialists and arbitration's results of both achievement test, and Used social network.

\section{E. Statistical Methods Used}

To achieve the study objectives, the researcher used the statistical package for Social Sciences SPSS to analyze the data and obtain the results as follows:

- Cronbach's Alpha reliability coefficient to measure study tool reliability

- Independent-Samples T- Test to identify the significant differences between the scores of the two groups: the experimental and control groups.

- Paired -Samples T- Test to find out the significant differences between the scores of the pre-application, and post application.

\section{Study RESUlts}

\section{A. First / Presentation of Study Results}

After completing the experiment, and conducting a post test, the data was analyzed to verify the study hypotheses as follows:

\section{1) First hypothesis}

There is no statistically significant difference at the significance level of (0.05) between the mean scores of The two groups female students: the experimental and control groups in the pre application of achievement test and to test the validity of this hypothesis, (T)Test was used to compare the mean scores of the two groups female students, the experimental and the control groups in the pre- application of achievement test as shown in the table below:

TABLE II: T-TEST FOR INDEPENDENT-SAMPLES

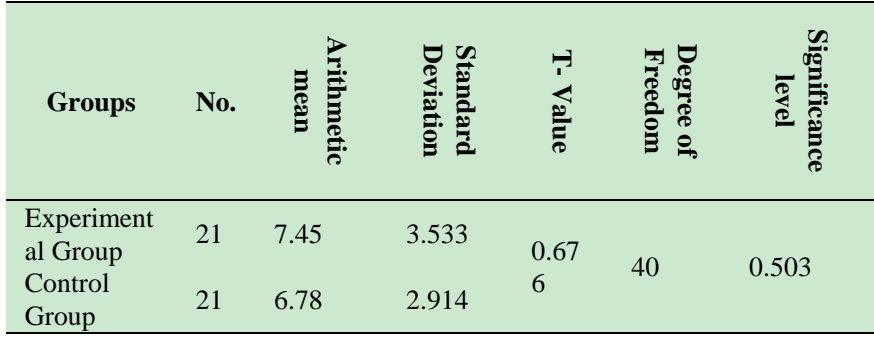

Table II shows arithmetic means and standard deviations of degrees of the two groups female students: the experimental and control groups, significance level of difference between them in the pre application of achievement test by using (T) test at the level of (0.05),where there are no statistically significant differences between them where the value of the significance level of (0.503); this means accepting the hypothesis and demonstrates the equivalence of the two study groups before using (Ning social network.

The following diagram shows arithmetic means of degrees of the two groups female students: the experimental and control groups in the pre application of achievement test.

\section{2) Second hypothesis}

There is a statistically significant difference at the significance level of (0.05) between the mean scores of the pre application and post application of achievement test among the control group.

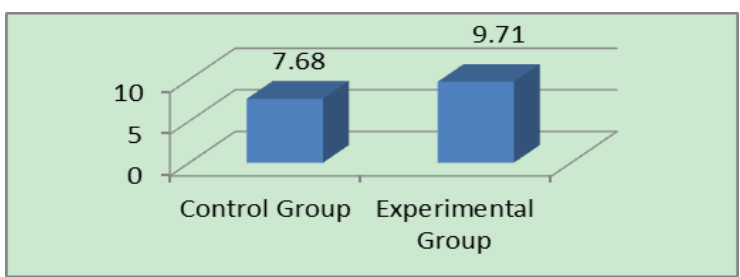

Fig. 6. A comparison between the mean scores of the two groups in the pre application.

To test the validity of this hypothesis, (Paired Samples T test) was used as shown in the following table:

TABLE III: PAIRED SAMPLES T-TEST

\begin{tabular}{cccccc}
$\overrightarrow{8}$ & $\begin{array}{c}\text { Arithmetic } \\
\text { mean }\end{array}$ & $\begin{array}{c}\text { Standard } \\
\text { Deviation }\end{array}$ & $\begin{array}{c}\text { T- } \\
\text { Value }\end{array}$ & $\begin{array}{c}\text { Degree } \\
\text { of } \\
\text { Freedom }\end{array}$ & $\begin{array}{c}\text { Significance } \\
\text { level }\end{array}$ \\
\hline
\end{tabular}

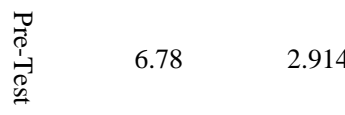

5.791- $\quad 20 \quad 0.000$

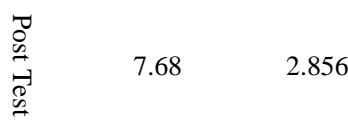

Table III shows the arithmetic means and standard deviations of the scores of the pre application and post application of achievement test among the control group and the level of significance of difference between them by using (T) Test that shows there are statistically significant differences at the level of (0.05) in favor of the post application and acceptance of hypothesis where the arithmetic mean of the post application was (7.68) while the arithmetic mean of the pre application was (6.78). This shows the effect of using the traditional method on the third secondary grade female students' achievement in English.

The following diagram shows the arithmetic means of the scores of the pre application and post application of achievement test among the control group.

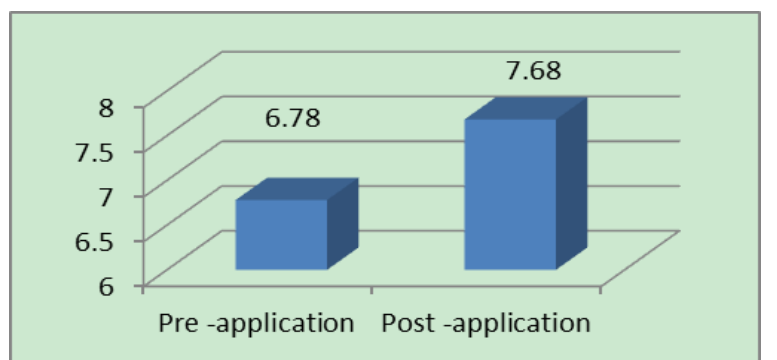

Fig. 8. A comparison between the mean scores of the pre and post application of the control group.

\section{3) Third hypothesis}

There is a statistically significant difference at the significance level of (0.05) between the mean scores of the pre application and post application of achievement test among the experimental group.

To test the validity of this hypothesis, (Paired Samples T 
test) was used as shown in the following table:

TABLE IV: PAIRED SAMPLES T-TEST

\begin{tabular}{lccccc}
\hline Test & $\begin{array}{c}\text { Arithmetic } \\
\text { mean }\end{array}$ & $\begin{array}{c}\text { Standard } \\
\text { Deviation }\end{array}$ & $\begin{array}{c}\text { T- } \\
\text { Value }\end{array}$ & $\begin{array}{c}\text { Degree } \\
\text { of } \\
\text { Freedom }\end{array}$ & $\begin{array}{c}\text { Significance } \\
\text { level }\end{array}$ \\
\hline $\begin{array}{l}\text { Pre-Tes } \\
\mathrm{t}\end{array}$ & 7.45 & 3.533 & & & \\
$\begin{array}{l}\text { Post } \\
\text { Test }\end{array}$ & 9.71 & 3.338 & $6.896-$ & 20 & 0.000 \\
\hline
\end{tabular}

Table IV. shows the arithmetic means and standard deviations of the scores of the pre application and post application of achievement test among the experimental group and the level of significance of difference between them by using $(\mathrm{T})$ Test that shows there are statistically significant differences at the level of (0.05) in favor of the post application and acceptance of hypothesis where the arithmetic mean of the post application was (9.71) while the arithmetic mean of the pre application was (7.45).

This shows the effect of using Ning Social Network on the third secondary grade female students' achievement in English.

The following diagram shows the arithmetic means of the pre application and post application of achievement test of the experimental group.

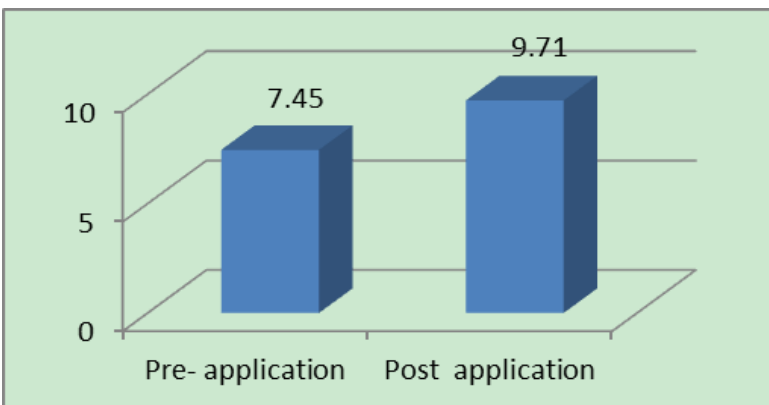

Fig. 9. A comparison between the mean scores of the pre and post application of the experimental group.

\section{4) Fourth hypothesis}

There is a statistically significant difference at the significance level of $(0.05)$ between the mean scores of the experimental group female students and the mean scores of the control group female students in the post application of achievement test in English course.

To test the validity of this hypothesis, (T) Test was used to compare the mean scores of the control and experimental groups in the post application of achievement test as shown in the following table:

TABLE V: T-TEST RESULTS OF (INDEPENDENT SAMPLES T TEST)

\begin{tabular}{|c|c|c|c|c|c|c|}
\hline Groups & No. & Е & 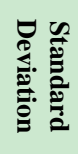 & ڤ్ & 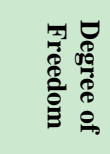 & 可 \\
\hline $\begin{array}{l}\text { Experimental } \\
\text { Group }\end{array}$ & 21 & 9.71 & 3.338 & \multirow{2}{*}{2.123} & \multirow{2}{*}{40} & \multirow{2}{*}{0.040} \\
\hline $\begin{array}{l}\text { Control } \\
\text { Group }\end{array}$ & 21 & 7.68 & 2.856 & & & \\
\hline
\end{tabular}

Table V. shows the arithmetic means and standard deviations of the scores of the experimental and control groups and the level of significance of difference between them by in the post application of achievement test by using (T) Test at the level of (0.05) that shows there are statistically significant differences between them where the value of significance level is (0.040) and this means accepting the hypothesis, this shows the effect of using Ning Social Network on the third secondary grade female students' achievement in English.

The following diagram shows the arithmetic means of the scores of the experimental and control groups in the post application of achievement test.

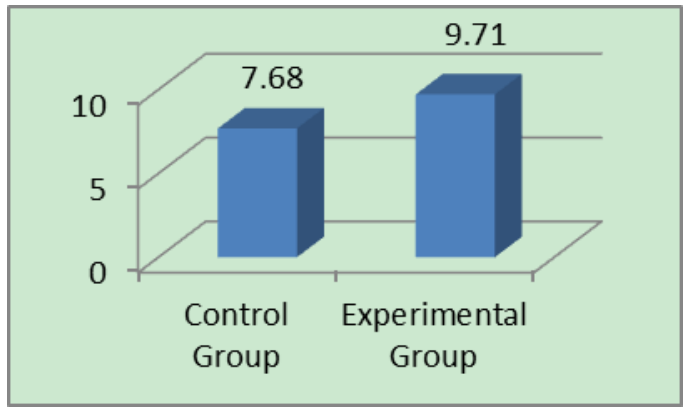

Fig. 10. A comparison between the mean scores of the two groups in the post application.

\section{B. Discussion of the Study Results}

The research results show that there are statistically significant differences for the experimental group that received learning through Ning social network This study is consistent with the studies of (Juang,2010) (Oradini \& Saunders, 2007) (Kamat \& Metha, 2009) (Brady \& others) (L.Lockyer \& J) which proved the effectiveness of using social networking in education [26]- [29]-[25]-[24]-[27].

The researcher attributed the effectiveness of using Ning social network on the third-grade secondary female students' achievement to a combination of several factors, including:

1) Easiness to deal with Ning social network where it doesn't need high computer skills among female students, and the similarity of its applications to those of popular networks; such as (Face Book), (MySpace), easy for female students to use.

2) Increasing the motivation to participate in learning; because of the students' fondness at this age to use technology, especially social networking.

3) Learning through Ning social network provides female students with an opportunity for more efficiency in learning; as it is not limited to a class time.

4) This technology supports cooperative learning by female students when engaged in group activity and upload it on the blog provided by Ning social network.

5) Using Ning social network promotes (constructivism) theory which makes the learner an active participator in learning and helps in survival of learning effect.

\section{CONCLUSION AND RECOMENDATIONS}

\section{A. Summary of the Study Results}

The study found the following results:

- There is no statistically significant difference at the significance level of (0.05) between the mean scores of the two groups of female students: the experimental and 
the control groups in the pre application of achievement test which indicates the equality of the two groups before conducting the experiment.

- There is a statistically significant difference at the significance level of (0.05) between the mean scores of the pre application and post application of achievement test of the control group in favor of the pre application.

- There is a statistically significant difference at the significance level of (0.05) between the mean scores of the pre application and post application of achievement test among the experimental group in favor of the post application.

- There is a statistically significant difference at the significance level of (0.05) between the mean scores of the experimental group female students, and the mean scores of the control group female students in the post application of achievement test in English course in favor of the experimental group.

\section{B. Conclusion and Recommendations}

Social Platforms can be used in teaching and learning to help students easily engage, collaborate and exchange information, using its creative \& sharing features. This study, along with other studies shown, have suggested some benefits of using social media especially with a good instructional framework. As for this study the ADDIE instructional design model was applied. In the light of the study results, the researcher recommends the need to:

1) Keep up with continuous technical progress, and invest the widespread use of social networks among students to obtain better learning outcomes.

2) Interest to meet the needs of a new generation of learners and increase motivation by providing attractive, technical, educational and funny means like social networks.

3) Transform from focus on teaching content of English into finding possible ways which enable students to engage in collaborative learning through the use of social networks in the learning process.

4) Take advantage of the educational potential of Ning social network in solving educational problems such as shortages of teachers or boredom faced by students.

5) Encourage and educate teachers to make use of social networks with various technologies, in order to improve the traditional teaching process based on direct education.

6) Provide free accounts on Ning network for teachers, by The Ministry of Education, which helps to strengthen the positive trend towards the use of this technique.

7) Educate students how to take advantage of educational possibilities of Ning social network and be taken seriously; to develop their skills in English outside the classroom and class.

8) Accelerate the integration of technology in education at various levels of education.

Based on the results of the present study, it was recommended to conduct the following studies:

1) Conducting studies; to demonstrate the effect of using Ning social network on achievement in other subjects.

2) Conducting a study to show the effect of using Ning social network on achievement of English course in the middle school.

3) Conducting a study to show the effect of using Ning social network as an equivalent and a complement to the traditional teaching method on achievement in English course.

4) Conducting a descriptive study to find out the attitude of teachers and students to use social networks in education.

5) Conducting studies on the most important criteria that should be met in educational social networks according to the nature of the educational stage.

\section{REFERENCES}

[1] A. M. Abdullah and A. Ahmad, Elearning Fundemntals \& Applications, 1st ed. AlRushd Publishers, Riyadh, 2005, pp. 103-112.

[2] A. S. Sahera, "The effect of using the internet on the student's desire to learn," 2008.

[3] S. Abdulhafez, "Electronic school \& new teachers roles of using the internet in students' achievement in the computer course in Al Quds Open University in Riyadh," Journal of Educational Sciences, vol. 6 , pp. 169-190, Jan. 2005.

[4] S. Adel, Individual Learning Technology and Creativity Development: Applied Vision, 1 st ed. Dar Wael Publishers, Amman, 2007, pp. 27-31.

[5] A. T. Awad, Electronic School \& New Teachers Roles, 1 st ed. AlRushd Publishers, Riyadh, 2009.

[6] A. Nawal and S. Elham, "E learning quality role in enhancing higher education quality," presented at the 4th International Conference for Elearning, Riyadh, KSA, March 2-5, 2015.

[7] K. Bader, Elearning Strategies, 1st ed. Dar Shuaa Publishers, Damascus, 2005.

[8] F. Wael, "Facebook effect on society," 1 st ed., March 2010.

[9] L. S. Vygotsky, Mind in Society, the Development of Higher Psychological Processes, Harvard Univ. Press, London, England, 1978.

[10] Z. Hasan, A New Vision in ELearning, 1 st ed. Al Dar Asawltiyah Publishers, Riyadh, 2005, pp. 29-31.

[11] B. Curtis and Z. Ke, "Empowering online learning: 100+activities for reading, reflecting, displaying, \& doing," 1st edition, Wiley San Francisco, pp. 220-235, 2008.

[12] A. H. Muhamed and Z. Mustafa et al., Education in KSA, A look at the present and Forward, AlRushd Publishers, Riyadh, 2002, pp. 92-113.

[13] Saudi Education policy document. [Online]. Available: https://goo.gl/azzXLc

[14] A. Richard, "The art of information of communications technology for teachers," David Fulton Publishers, pp. 66-71.

[15] T. O'Reilly. (2005). What is web 2.0 design patterns and business models for the next generation of software. [Online]. Available: http://www.oreillynet.com/lpt/a/622

[16] A. Amoudi, "Social software in the web-based learning system: social networks as a model," presented at the 1 st International Conference for e-learning \& distance learning, Riyadh, March 16-18, 2011.

[17] Hitwise. (2008). Hitwise US Social Networking Report. [Online]. Available: https://goo.gl/kbCW95

[18] Digizen. (2008). On the classification of Social Networks. [Online] Available: http://www.digizen.org/

[19] E. Eric. (2010). Creating a community of learners using ning.com a study into the pedagogical - educational value of social networking in a large multi-section introductory media arts and science course at IUPUI [Online]. Available: https://goo.gl/nJWsYV

[20] D. Craig and E. Anthony. (2010). Using social networks in learning and teaching in higher education: An Australian case study. [Online]. Available: http://www.igi-global.com/article/international-journal-

[21] M. Sacide and U. Yasemin. (2009). The usage of social networks in educational context. [Online]. Available: https://goo.g1/9LGRlG

[22] W. M. Alison. (2007). Student attitudes towards social networks and learning modalities. [Online]. Available: https://goo.gl/AaQsP

[23] E. Funda and T. Filiz. (2011). Use of social networks as an educational tool. [Online]. Available: http://www.cedtech.net/past2.asp?numara=22

[24] B. P. Kevin et al., (2010). The use of alternative social networking sites in higher educational settings: A case study of the e-learning benefits of ning in education. [Online]. Available: http://www.ncolr.org/jiol/issues/pdf/9.2.4.pdf 
[25] K. Vasudha and M. Devica. (2009). Effectiveness of social software tool "face book" in learning. [Online]. Available: https://goo.gl/NrJav9

[26] Y.-R. Juang. (2008). Integrating social networking site into teaching and learning. [Online]. Available: https://goo.gl/wc7pyH

[27] L. Lockyer and J. Patterson. (2008). Integrating social networking technologies in education: A case study of a formal learning environment. [Online]. Available: https://goo.gl/XIt3d9

[28] A. Areej, "Electronic school \& new teachers roles of podcast in developing EFL students' speaking skills," MA. dissertation, Dept. Elect. Eng., KAA Univ. Jeddah, Saudi Arabia, 2009.

[29] O. Federica and S. Gunter. (2007). The use of social networking by students and staff in / higher education. [Online]. Available: https://goo.gl/c0XPTN
[30] A. Ajay. (2011). To investigate the usage of social networking sites as a career enhancement tool among generation Y: An empirical research. [Online]. Available: https://goo.gl/Hms $3 \mathrm{Xj}$

[31] A. G. Ismaiel, Elearning; from Application to Professionalism \& Quality, 1st ed. 2009, pp. 43-52.

Haya Suliman Al Jasser is an EFL teacher \& an instructional technology \& elearning specialist at MOE. She is currently pursuing a $\mathrm{PhD}$ degree in curriculum \& instruction in the College of Education at King Saud University (KSU) in Riyadh, Saudi Arabia. She received a master's degree in instructional technology in 2012 and a bachelor's degree in English language \& literature. 